\title{
Enhanced thermoelectric performance of Na-doped PbTe synthesized under high pressure
}

\author{
Bowen Cai, Jianghua Li, Hao Sun, Long Zhang, Bo Xu*, Wentao Hu, Dongli Yu, Julong He, \\ Zhisheng Zhao, Zhongyuan Liu and Yongjun Tian*
}

\begin{abstract}
Despite an effective p-type dopant for PbTe, the low solubility of Na limits the fully optimization of thermoelectric properties of $\mathrm{Na}$-doped $\mathrm{PbTe}$. In this work, $\mathrm{Na}$-doped $\mathrm{PbTe}$ was synthesized under high pressure. The formation of the desired rocksalt phase with substantially increased $\mathrm{Na}$ content leads to a high carrier concentration of $3.2 \times 10^{20} \mathrm{~cm}^{-3}$ for $\mathrm{Na}_{0.03} \mathrm{~Pb}_{0.97} \mathrm{Te}$. Moreover, dense in-grain dislocations are identified from the microstructure analysis. Benefited from the improved power factor and greatly suppressed lattice thermal conductivity, the maximal $Z T$ of 1.7 is achieved in the optimal $\mathrm{Na}_{0.03} \mathrm{~Pb}_{0.97} \mathrm{Te}$. Current work thus designates the advantage of high pressure in synthesizing PbTe-based thermoelectric materials.
\end{abstract}

Keywords: lead telluride, high pressure synthesis, carrier concentration, dislocation

\section{INTRODUCTION}

Thermoelectric materials, which can directly convert heat to electricity and vice versa, are appealing candidates for alternative and complementary energy sources [1-4]. The performance of a thermoelectric material for energy conversion relies on its dimensionless figure of merit, $Z T=S^{2} T / \rho \kappa$, where $S, T, \rho$ and $\kappa$ are the Seebeck coefficient, temperature, electrical resistivity and thermal conductivity, respectively. It is technically challenging to enhance $Z T$ due to the adversely dependence among $S, \rho$ and $\kappa$. Nonetheless, significant progresses have been achieved during the past decades through a variety of strategies, e.g., phonon-glass electron-crystal strategy [5], electronic band engineering [6,7], nanostructure engineering [8,9], and modulation doping $[10,11]$, in a broader range of materials systems $[12,13]$.

Rocksalt-structured $\mathrm{PbTe}$ and related materials (both $\mathrm{n}$-type and p-type) are excellent thermoelectric materials working in the mid-temperature region, which have been investigated and successfully used for several NASA space missions since 1960s [14,15]. A diversity of approaches have been applied to PbTe-based materials for ZT enhancements, such as carrier concentration optimization $[16,17]$, introduction of resonance level $[18,19]$, electronic band engineering $[6,20,21]$ and microstructure engineering $[8,22]$. Recent researches also highlight lattice dislocations as an effective phonon scattering source to further suppress the lattice thermal conductivity of lead chalcogenides [23-26]. For PbTe, the monovalent sodium has been verified as the most viable p-type dopant [17]. Still, the low solubility of $\mathrm{Na}$ in $\mathrm{PbTe}$ limits to regulate the hole concentration $[15,21,27,28]$, which is unfavorable for optimizing the electrical property of Na-doped $\mathrm{PbTe}$.

Usually, $\mathrm{Na}$-doped $\mathrm{PbTe}$ samples are synthesized with melting-quenching methods under ambient conditions. High pressure has been widely applied to materials synthesis, with demonstrated effectiveness in thermoelectric materials synthesis and performance optimization [29-33]. High pressure can initiate significant changes in the reaction equilibrium, lower the reaction temperature, and facilitate the reaction [34,35]. The presence of high pressure can effectively broaden the phase space where traditional metallurgy and melt-growth fail, thus beneficial to increase the solubility. It was confirmed that high pressure can increase the solid solubility of solute in the solid solution [36]. In addition, high pressure can induce plastic deformation and promote the formation of dislocations [37]. In this work, $\mathrm{Na}$-doped $\mathrm{PbTe}$ samples were produced with high pressure synthesis (HPS). Under high pressure, a remarkable increase of $\mathrm{Na}$ solubility in $\mathrm{PbTe}$ and highly densified in-grain dislocations leads to enhanced power factor and suppressed lattice thermal conductivity. As a result, the optimal $\mathrm{Na}_{0.03} \mathrm{~Pb}_{0.97} \mathrm{Te}$ sam-

State Key Laboratory of Metastable Materials Science and Technology, Yanshan University, Qinhuangdao 066004, China

* Corresponding authors (emails: bxu@ysu.edu.cn (Xu B); fhcl@ysu.edu.cn (Tian Y)) 
ple shows the highest $Z T$ of 1.7 at temperature higher than $740 \mathrm{~K}$.

\section{EXPERIMENTAL SECTION}

\section{Sample preparation}

High purity $\mathrm{Na}$ (99.95\%, chunk), $\mathrm{PbTe}$ (99.999\%, granule, 1-10 $\mathrm{mm}$ ) and $\mathrm{Te}(99.999 \%$, powder, $200 \mathrm{mesh})$ were mixed according to the molecular ratios of $x: 1-x: x$ ( $x=$ $0.01,0.02$, and 0.03 ). The mixtures were cold-pressed into cylinders for high pressure experiments with a six-anvil high pressure apparatus (CS-1B, working pressure 1-6 GPa, working temperature $300-2,300 \mathrm{~K}$ ). The reaction temperature was measured with a thermocouple. The pressure was pre-calibrated with the high-pressure phase transitions of metals $\mathrm{Bi}$ and $\mathrm{Ba}$, which were determined from the sudden change in the measured electrical resistance. A two-step HPS process was employed to improve the sample homogeneity. The first step of HPS was carried out at $4 \mathrm{GPa}$ and $1,073 \mathrm{~K}$ for $0.5 \mathrm{~h}$. The semiproduct was ground into powders, shaped with cold press, and loaded into high pressure apparatus for the second step of HPS ( $4 \mathrm{GPa}$ and $1,073 \mathrm{~K}$ for $1 \mathrm{~h}$ ). The HPS product again was ground into powders and consolidated into a dense pellet $(\phi 10.7 \mathrm{~mm} \times 8 \mathrm{~mm})$ under conditions of $4 \mathrm{GPa}$ and $853 \mathrm{~K}$ for $0.5 \mathrm{~h}$. The mixing, grinding, and shaping of the raw and intermediate materials were performed in the glovebox under argon protection.

\section{Structure and composition}

Crystal structure and morphology of the final products were characterized with X-ray diffraction (XRD, Rigaku D/MAX/2500/PC) and scanning electron microscopy (SEM, Hitachi S-4800 II FESEM) equipped with energydispersive X-ray spectroscopy (EDS), respectively. The chemical compositions were determined with electron probe microanalysis (EPMA, JEOL JXA-8230). The microstructures of the samples were characterized by transmission electron microscopy (TEM, FEI Titan ETEM G2) with an accelerating voltage of $300 \mathrm{kV}$. The TEM samples were prepared with focused ion beam (FIB, FEI Scios), and cleaned by argon ion mill (Leica EM RES102) after FIB sampling.

\section{Thermoelectric properties}

Rectangular blocks $\left(2 \times 2 \times 8 \mathrm{~mm}^{3}\right)$, disks $(\phi 6 \mathrm{~mm}$ $\times 1.5 \mathrm{~mm})$, and slices $\left(2.5 \times 0.5 \times 8 \mathrm{~mm}^{3}\right)$ were cut from the final pellets for the electrical transport, thermal conductivity, and Hall measurements, respectively. The Seebeck coefficient and electrical resistivity were measured

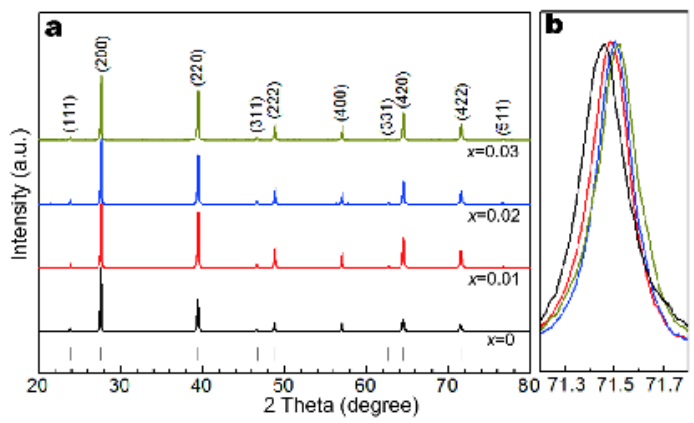

Figure 1 (a) XRD patterns of $\mathrm{Na}_{x} \mathrm{~Pb}_{1-x} \mathrm{Te}$ samples prepared under high pressure. (b) The normalized and magnified (422) peak showing the systematic shift to higher angle with increasing $\mathrm{Na}$ content.

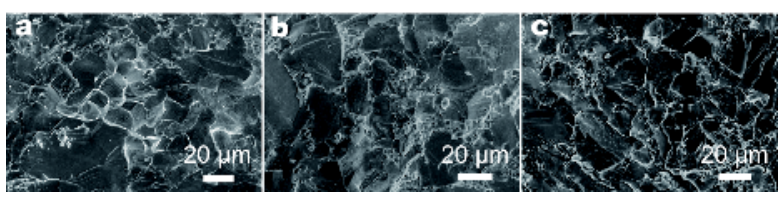

Figure 2 Typical SEM images from the fractured surfaces of $\mathrm{Na}_{x} \mathrm{~Pb}_{1-x} \mathrm{Te}$ samples. (a) $x=0.01$, (b) $x=0.02$, (c) $x=0.03$.

with a ZEM-3 apparatus (Ulvac-Riko). The thermal diffusivity $\alpha$ was measured with a TC-9000H apparatus (Ulvac-Riko), the sample density $d$ was determined with the Archimedes method, and the heat capacity in the unit of $k_{\mathrm{B}}$ per atom was estimated by $C_{\mathrm{p}}=3.07+4.7 \times 10^{-4} \times(\mathrm{T}$ -300 ) for lead chalcogenides with an uncertainty of $2 \%$ at temperature higher than $300 \mathrm{~K}[17,23]$. The thermal conductivity was calculated as $\kappa=\alpha d C_{\mathrm{p}}$. The uncertainties in $S, \rho$ and $\kappa$ are less than $5 \%$. The room-temperature Hall measurement was conducted with a Physical Property Measurement System (PPMS, Quantum Design).

\section{RESULTS AND DISCUSSION}

XRD patterns of $\mathrm{PbTe}$ and $\mathrm{Na}$-doped $\mathrm{PbTe}$ samples are demonstrated in Fig. 1a. All the main peaks can be attributed to the rocksalt structure of symmetry with no apparent diffraction peak from secondary phases detected. Our HPS samples are thus predominated by the rocksalt phase. The diffraction peaks systematically shift to larger angles with increasing $\mathrm{Na}$ doping level, as illustrated in Fig. $1 \mathrm{~b}$ for the normalized and magnified (422) peak, indicating a shrinking lattice constant due to the incorporation of more $\mathrm{Na}$ atoms on $\mathrm{Pb}$ sites of the crystal lattice (Table 1). Fig. 2 shows SEM images from the freshly fractured surfaces of $\mathrm{Na}_{x} \mathrm{~Pb}_{1-x} \mathrm{Te}$ samples. All the samples display similar morphology. The grains are well sintered with no obvious pore or microcrack, which is 


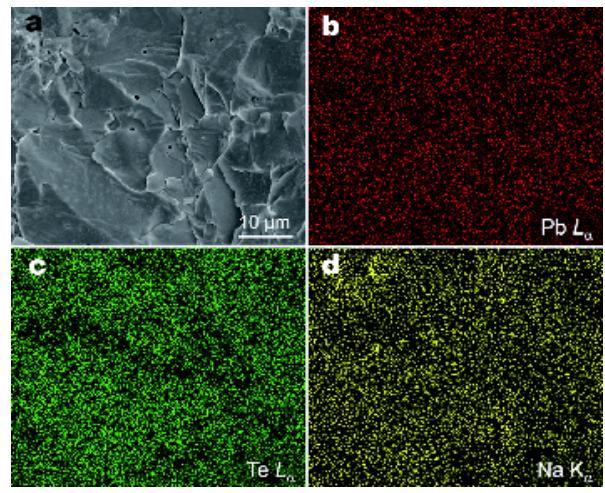

Figure 3 EDS elemental mapping of $\mathrm{Na}_{0.03} \mathrm{~Pb}_{0.97} \mathrm{Te}$ sample. (a) SEM image. (b-d) The corresponding elemental mapping of $\mathrm{Pb}, \mathrm{Te}$, and $\mathrm{Na}$, respectively.

consistent with the high density of our HPS samples ( $>96 \%$ of the theoretical density). The SEM-EDS elemental mapping (Fig. 3) shows all the elements, i.e., $\mathrm{Pb}$, $\mathrm{Te}$, and $\mathrm{Na}$, are almost uniformly distributed throughout the whole region, indicating a homogeneous composition achieved in the HPS sample.

The room temperature properties of $\mathrm{Na}_{x} \mathrm{~Pb}_{1-x} \mathrm{Te}$ samples are summarized in Table 1. The EPMA determined $\mathrm{Na}$ contents are very close to the nominal values, indicating an effective incorporation of $\mathrm{Na}$ into the crystal lattice under high pressure. The Hall measurements show that all the samples are dominated with charge carriers of holes. With increasing $\mathrm{Na}$ doping level, more holes are introduced into the system, leading to increasing hole concentration and decreasing electrical resistivity. Due to the high pressure that can improve the solid solubility of solute into the solid solution, the highest $\mathrm{Na}$ doping level achieved in our HPS samples, i.e., 0.027 as determined from EPMA, is beyond the solid solubility of $\mathrm{Na}$ in $\mathrm{PbTe}$ under ambient pressure [28]. As a result, the hole concentration of $3.2 \times 10^{20} \mathrm{~cm}^{-3}$ is achieved in $\mathrm{Na}_{0.03} \mathrm{~Pb}_{0.97} \mathrm{Te}$, which is much higher than those achieved in state-of-theart p-type $\mathrm{PbTe}$ materials synthesized under ambient pressure $[8,17,38] . \mathrm{Na}_{0.03} \mathrm{~Pb}_{0.97} \mathrm{Te}$ also shows a larger Seebeck coefficient than that of the two less doped sam- ples. The enhancement of the Seebeck coefficient at high hole concentration can be explained with a two-band model $[17,39]$. For PbTe system, the two valence bands near the Fermi level are the light $L$ and heavy $\Sigma$ bands. While the light band dominates the Seebeck coefficient at low hole concentration, the heavy band contributes significantly at high hole concentration, leading to the enhanced Seebeck coefficient. A single parabolic band (SPB) model within the acoustic phonon scattering approximation can be used to roughly estimate the carrier effective mass, $m^{*}$, of $\mathrm{Na}_{x} \mathrm{~Pb}_{1-x} \mathrm{Te}$ samples. In the SPB model, the Seebeck coefficient is related to the carrier concentration through the following equations: $S=\left(k_{\mathrm{B}} / \mathrm{e}\right)$ $\left(2 F_{1}(\xi) / F_{0}(\xi)-\xi\right)$ and $p=4 \pi\left(2 m^{*} k_{\mathrm{B}} T / h^{2}\right)^{3 / 2} F_{1 / 2}(\xi)$, where $\xi, k_{\mathrm{B}}$, and $h$ are the reduced Fermi energy, Boltzmann constant, and Planck constant, respectively, $F_{\mathrm{j}}(\xi)=\int_{0}^{\infty} v^{j} \mathrm{~d} v /\left(1+\mathrm{e}^{v-\xi}\right)$ is the Fermi integral of order $\mathrm{j}$ with $v$ being the reduced carrier energy [40]. The estimated effective mass is listed in Table 1. The large $m^{*}$ of $\mathrm{Na}_{0.03} \mathrm{~Pb}_{0.97} \mathrm{Te}$ clearly indicates substantial contribution from the heavy band. In comparison, $m^{*}$ for $2 \% \mathrm{Na}$ doped $\mathrm{PbTe}$ synthesized under ambient pressure are $0.83 m_{\mathrm{e}}$ [8] and $0.79 \mathrm{~m}_{\mathrm{e}}$ [17], very close to $0.88 \mathrm{~m}_{\mathrm{e}}$ of the corresponding HPS sample.

The temperature dependent thermoelectric properties of $\mathrm{Na}_{x} \mathrm{~Pb}_{1-x} \mathrm{Te}$ samples from HPS are displayed in Fig. 4. Representative results of $2 \% \mathrm{Na}$-doped $\mathrm{PbTe}$ samples synthesized under ambient pressure from literature are also included for comparison $[8,17,27]$. As shown in Fig. $4 \mathrm{a}$, the electrical resistivity increases monotonically with increasing temperature, indicating a heavily doped semiconductor behavior. Also, the electrical resistivity decreases with increasing $\mathrm{Na}$ content due to the increment in carrier concentration. A plateau-like feature appears in the resistivity of $\mathrm{Na}_{0.03} \mathrm{~Pb}_{0.97} \mathrm{Te}$ at temperature higher than $600 \mathrm{~K}$. Similar features were previously observed in heavily doped $\mathrm{PbTe}$ materials [8,41], which are attributed to the onset of $\mathrm{Na}$ diffusion at high temperature. Note the electrical resistivities of $2 \% \mathrm{Na}$-doped samples from different fabrication methods vary substantially from sample to sample, which may connect with the specific fabrication process of each sample

Table 1 Nominal and EPMA-determined sodium contents, lattice parameter $(a, \AA)$, electrical resistivity $(\rho, \mu \Omega \mathrm{m})$, Seebeck coefficient $\left(S, \mu \mathrm{V} \mathrm{K}^{-1}\right)$, carrier concentration $\left(p, 10^{20} \mathrm{~cm}^{-3}\right)$, carrier mobility $\left(\mu, \mathrm{cm}^{2} \mathrm{~V}^{-1} \mathrm{~s}^{-1}\right)$, and effective mass $\left(m^{*}, m_{\mathrm{e}}\right)$ of $\mathrm{Na}_{x} \mathrm{~Pb}_{1-x} \mathrm{Te}(x=0.01,0.02$, and 0.03$)$ samples measured at room temperature

\begin{tabular}{cccccccc}
\hline Nominal & EPMA & $a$ & $\rho$ & $S$ & $p$ & $\mu$ & $m^{*}$ \\
\hline 0.01 & 0.009 & 6.4586 & 9.6 & 63 & 0.8 & 81 & 0.57 \\
0.02 & 0.017 & 6.4574 & 4.1 & 53 & 2.0 & 76 & 0.88 \\
0.03 & 0.027 & 6.4560 & 3.4 & 72 & 3.2 & 57 & 1.66 \\
\hline
\end{tabular}



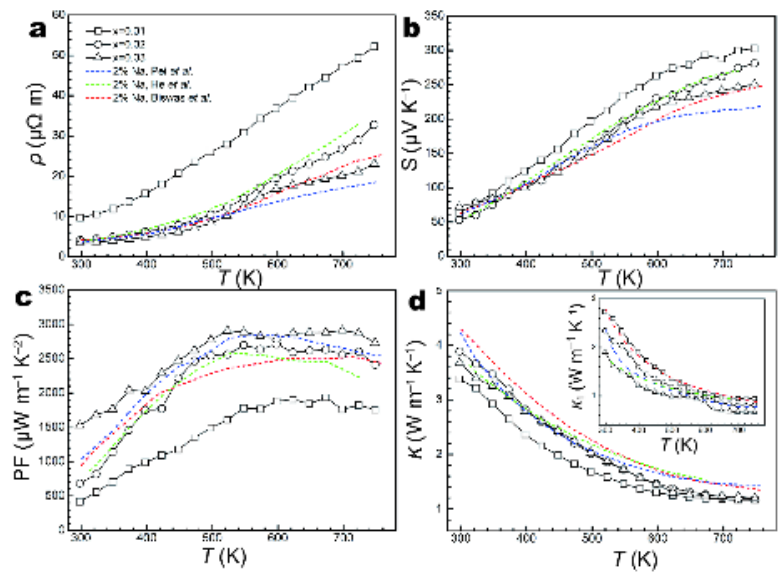

Figure 4 The temperature dependent thermoelectric properties of $\mathrm{Na}_{x} \mathrm{~Pb}_{1-x}$ Te samples. (a) Electrical resistivity. (b) Seebeck coefficient. (c) Power factor. (d) thermal conductivity. The inset of panel $d$ shows the lattice thermal conductivity.

\section{$[8,17,27]$.}

All the samples show positive Seebeck coefficient, indicating a p-type conduction (Fig. 4b). At low temperature, the largest Seebeck coefficient is achieved in $\mathrm{Na}_{0.03} \mathrm{~Pb}_{0.97} \mathrm{Te}$ due to the heavy band contribution at high hole concentration. However, the variation of the Seebeck coefficient as a function of $\mathrm{Na}$ content (and hole concentration) restores the general trend at high temperature: The higher the hole concentration, the lower the Seebeck coefficient. This is due to the temperature dependent band offset between the light and heavy bands of PbTe: The light band falls below the heavy band at ca. $450 \mathrm{~K}$ [42]. The temperature dependent power factor, $\mathrm{PF}=S^{2} / \rho$, of $\mathrm{Na}_{x} \mathrm{~Pb}_{1-x} \mathrm{Te}$ samples is shown in Fig. $4 \mathrm{c}$. $\mathrm{PF}$ increases with elevating $\mathrm{Na}$ doping level. $\mathrm{Na}_{0.03} \mathrm{~Pb}_{0.97} \mathrm{Te}$ exhibits the best power factor among all the samples, which is $1,500 \mu \mathrm{W} \mathrm{m} \mathrm{m}^{-1} \mathrm{~K}^{-2}$ at room temperature and rises to values close to $2,900 \mu \mathrm{W} \mathrm{m} \mathrm{m}^{-1} \mathrm{~K}^{-2}$ at temperatures higher than $500 \mathrm{~K}$. Compared with those ambient pressure synthesized samples, the improved power factor achieved in $\mathrm{Na}_{0.03} \mathrm{~Pb}_{0.97} \mathrm{Te}$ can be attributed to the balance between electrical resistivity and Seebeck coefficient occurring at higher hole concentration.

Fig. 4d presents the temperature dependent thermal conductivity of $\mathrm{Na}_{x} \mathrm{~Pb}_{1-x} \mathrm{Te}$ samples. The thermal conductivity decreases with increasing temperature but does not show an explicit dependence on $\mathrm{Na}$ content. The total thermal conductivity $\kappa$ is a sum of the electronic contribution $\kappa_{\mathrm{e}}$ and the lattice thermal conductivity $\kappa_{\mathrm{l}}$. In $\mathrm{Na}$ doped $\mathrm{PbTe}$ samples, the substitutional $\mathrm{Na}$ atoms can introduce holes to increase $\kappa_{\mathrm{e}}$ and scatter phonons to suppress $\kappa_{1}$. The rapidly increased $\kappa_{\mathrm{e}}$ may offset the decrease in $\kappa_{1}$, resulting in larger thermal conductivity at higher $\mathrm{Na}$ content. $\kappa_{\mathrm{e}}$ can be estimated with the Wiedemann-Franz law $\left(\kappa_{\mathrm{e}}=L T / \rho\right.$, where $L$ is the Lorenz number) from the measured electrical resistivity. It is not easy to accurately determine $L$ of $\mathrm{PbTe}$ due to the complexity such as non-parabolic Kane bands, multiple bands, and alternate scattering mechanisms. Here we use a simple empirical formula, $L=1.5+\exp (-|\mathrm{S}| / 116)$, to estimate $L$ (in the unit of $10^{-8} \mathrm{~W} \Omega \mathrm{K}^{-2}$ ) from the Seebeck coefficient (in the unit of $\mu \mathrm{V} \mathrm{K}{ }^{-1}$ ) with an acceptable accuracy [43]. $\kappa_{1}$ can then be calculated by subtracting $\kappa_{\mathrm{e}}$ from $\kappa$. The inset to Fig. $4 \mathrm{~d}$ shows $\kappa_{1}$ of $\mathrm{Na}_{x} \mathrm{~Pb}_{1-x}$ Te samples. Clearly, the lattice thermal conductivity decreases with increasing $\mathrm{Na}$ content. Our HPS $\mathrm{Na}_{0.02} \mathrm{~Pb}_{0.97}$ Te exhibits a lattice thermal conductivity lower $[8,27]$ or comparable to [17] those of ambient pressure synthesized samples at high temperature. $\kappa_{1}$ for $\mathrm{Na}_{0.03} \mathrm{~Pb}_{0.97} \mathrm{Te}$ drops further and reaches the minimum value of $0.67 \mathrm{~W} \mathrm{~m}^{-1} \mathrm{~K}^{-1}$ at temperature higher than $700 \mathrm{~K}$, which is one of the lowest value achieved in single elemental doped PbTe. Higher $\mathrm{Na}$ content can introduce more point defects to increase phonon scattering and lower lattice thermal conductivity. Other phonon scattering mechanisms, such as nanoinclusions, dislocations, may also contribute to the reduction of lattice thermal conductivity.

To declare other possible phonon scattering mechanisms, the microstructure of $\mathrm{Na}_{0.03} \mathrm{~Pb}_{0.97} \mathrm{Te}$ was investigated with TEM. The dark field TEM image displays numerous sand-like features (Fig. 5a), which are attributed to highly densified dislocations and lattice distortion as revealed from the HRTEM observations. An HRTEM image viewed along the zone axis is shown in Fig. 5b, where no obvious nanoinclusion or nanoprecipitate is identified. The inset to Fig. $5 \mathrm{~b}$ shows the corresponding fast Fourier transform (FFT) pattern. Split $\{111\}$ diffraction spots are observed, indicating significant lattice distortion in $\{111\}$ lattice. Fig. 5c displays the inverse FFT (IFFT) image from selected $\{111\}$ diffraction spots, revealing the highly densified dislocations and remarkable lattice distortion. Similar dislocations and lattice distortion but to a less extent can also be revealed from the FFT-filtered image by selecting $\{002\}$ spots (Fig. $5 d$ ). The plastic deformation process under high pressure facilitates the formation of dense in-grain dislocations, which can scatter mid-frequency phonons and further lower the lattice thermal conductivity [23-25,44].

The temperature dependent $Z T$ of $\mathrm{Na}_{x} \mathrm{~Pb}_{1-x} \mathrm{Te}$ samples is calculated on the basis of thermoelectric properties and demonstrated in Fig. 6. Typical results from $\mathrm{Na}_{0.02} \mathrm{~Pb}_{0.98} \mathrm{Te}$ 


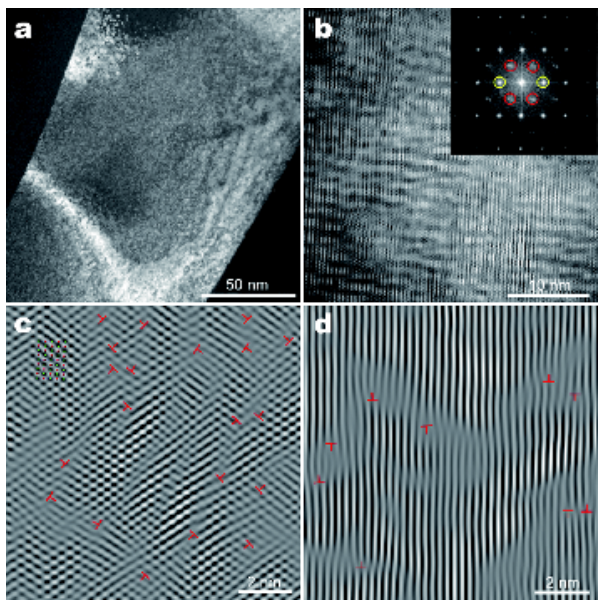

Figure 5 (a) The dark field TEM image of a lamellar particle of $\mathrm{Na}_{0.03} \mathrm{~Pb}_{0.97} \mathrm{Te}$, showing the highly densified dislocations and lattice distortion. (b) HRTEM image and corresponding FFT pattern (inset) viewed along zone axis of particle shown in (a). In FFT pattern, the $\{111\}$ diffraction spots (red circles in (b)) are split. (c) IFFT image from selected $\{111\}$ diffraction spots, showing the highly densified dislocations and remarkable lattice distortion in $\{111\}$ lattices. (d) IFFT image from selected $\{002\}$ diffraction spots (yellow circles in (b)), showing additional dislocations and lattice distortion in $\{002\}$ lattices.

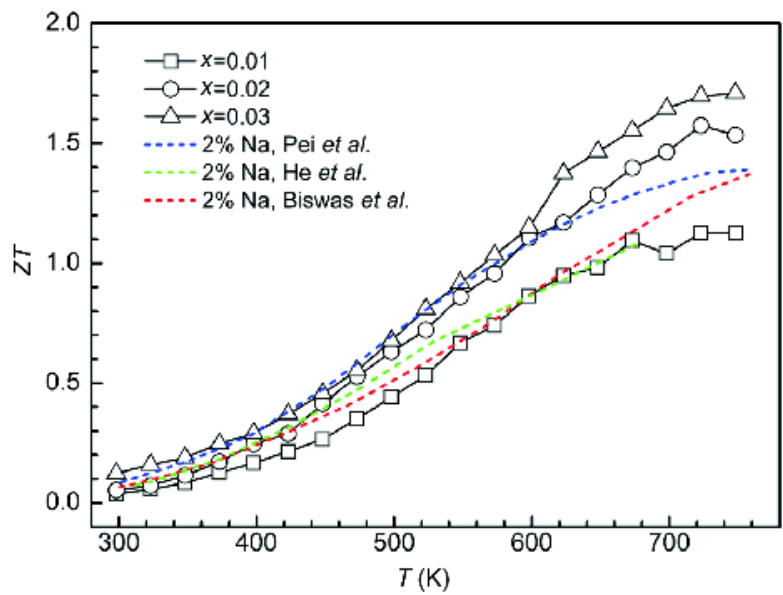

Figure 6 The temperature dependent thermoelectric figure of merit of $\mathrm{Na}_{x} \mathrm{~Pb}_{1-x} \mathrm{Te}(x=0.01,0.02$, and 0.03$)$.

samples from literature are also presented $[8,17,27]$. The high pressure synthesized samples show excellent thermoelectric performance. The highest $Z T$ reaches 1.7 in the optimal $\mathrm{Na}_{0.03} \mathrm{~Pb}_{0.97} \mathrm{Te}$ at temperature high than $740 \mathrm{~K}$. In comparison, $Z T$ for HPS $\mathrm{Na}_{0.02} \mathrm{~Pb}_{0.98} \mathrm{Te}$ peaks at 1.57 , slightly higher than that achieved in ambient-pressure synthesized samples with the same $\mathrm{Na}$ doping level. The HPS method employed in current work shows several advantages compared with ambient-pressure synthesis methods. It provides a prompt fabrication method to the final products. High pressure promotes the doping process and increase the solubility of $\mathrm{Na}$ in $\mathrm{PbTe}$, leading to much higher hole concentration $\left(3.2 \times 10^{20} \mathrm{~cm}^{-3}\right.$ for $\mathrm{Na}_{0.03} \mathrm{~Pb}_{0.97} \mathrm{Te}$ ) and mildly enhanced power factor. Moreover, high pressure facilitates the formation of dense ingrain dislocations, which further suppress the lattice thermal conductivity.

\section{CONCLUSIONS}

p-Type Na-doped PbTe samples were successfully synthesized with high pressure synthesis. Due to the presence of high pressure, $\mathrm{Na}$ solubility in $\mathrm{PbTe}$ is substantially improved compared with those ambient-pressure synthesized samples, meanwhile abundant dislocations are formed within the grains. For the optimal $\mathrm{Na}_{0.03} \mathrm{~Pb}_{0.97} \mathrm{Te}$, the power factor reaches $2,900 \mu \mathrm{W} \mathrm{m} \mathrm{K}^{-1} \mathrm{~K}^{-2}$ at temperature higher than $500 \mathrm{~K}$. Combined with the greatly suppressed lattice thermal conductivity (ca. $0.7 \mathrm{~W} \mathrm{~m}^{-1} \mathrm{~K}^{-1}$ in the high temperature region), a $Z T$ value as high as 1.7 is achieved. High pressure synthesis thus offers an effective approach to synthesizing $\mathrm{PbTe}$-based thermoelectric materials. Further enhancement in thermoelectric performance of $\mathrm{PbTe}$-based thermoelectric materials can be expected through combining HPS with strategies of band structure and microstructure engineering.

\section{Received 20 February 2018; accepted 27 March 2018; published online 18 April 2018}

1 Shi X, Chen L, Uher C. Recent advances in high-performance bulk thermoelectric materials. Int Mater Rev, 2016, 61: 379-415

2 Tan G, Zhao LD, Kanatzidis MG. Rationally designing high-performance bulk thermoelectric materials. Chem Rev, 2016, 116: 12123-12149

3 He J, Tritt TM. Advances in thermoelectric materials research: Looking back and moving forward. Science, 2017, 357: eaak9997

4 Yang L, Chen ZG, Dargusch MS, et al. High performance thermoelectric materials: progress and their applications. Adv Energy Mater, 2017, 7: 1701797

5 Slack GA. New Materials and Performance Limits for Thermoelectric Cooling. CRC Handbook of Thermoelectrics, 1995, 407440

6 Pei Y, Shi X, LaLonde A, et al. Convergence of electronic bands for high performance bulk thermoelectrics. Nature, 2011, 473: 66-69

7 Hong M, Chen ZG, Yang L, et al. Enhancing the thermoelectric performance of $\mathrm{SnSe}_{1-x} \mathrm{Te}_{x}$ nanoplates through band engineering. J Mater Chem A, 2017, 5: 10713-10721

8 Biswas K, He J, Blum ID, et al. High-performance bulk thermoelectrics with all-scale hierarchical architectures. Nature, 2012, 489: 414-418

9 Poudel B, Hao Q, Ma Y, et al. High-thermoelectric performance of nanostructured bismuth antimony telluride bulk alloys. Science, 
2008, 320: 634-638

10 Zebarjadi M, Joshi G, Zhu G, et al. Power factor enhancement by modulation doping in bulk nanocomposites. Nano Lett, 2011, 11: 2225-2230

$11 \mathrm{Yu} \mathrm{B}$, Zebarjadi M, Wang H, et al. Enhancement of thermoelectric properties by modulation-doping in silicon germanium alloy nanocomposites. Nano Lett, 2012, 12: 2077-2082

12 Sun F-H, Dong J, Dey S, et al. Enhanced thermoelectric performance of $\mathrm{Cu}_{12} \mathrm{Sb}_{4} \mathrm{~S}_{13-\delta}$ tetrahedrite via nickel doping. Sci China Mater, 2018, DOI: 10.1007/s40843-018-9241-x

13 Sun X, Wei Y, Li J, et al. Ultralight conducting PEDOT:PSS/carbon nanotube aerogels doped with silver for thermoelectric materials. Sci China Mater, 2017, 60: 159-166

14 Pei Y, Lensch-Falk J, Toberer ES, et al. High thermoelectric performance in $\mathrm{PbTe}$ due to large nanoscale $\mathrm{Ag}_{2} \mathrm{Te}$ precipitates and $\mathrm{La}$ doping. Adv Funct Mater, 2011, 21: 241-249

15 LaLonde AD, Pei Y, Wang $\mathrm{H}$, et al. Lead telluride alloy thermoelectrics. Mater Today, 2011, 14: 526-532

16 Pei Y, Gibbs ZM, Gloskovskii A, et al. Optimum carrier concentration in $\mathrm{n}$-Type PbTe thermoelectrics. Adv Energy Mater, 2014, 4: 1400486

17 Pei Y, LaLonde A, Iwanaga S, et al. High thermoelectric figure of merit in heavy hole dominated PbTe. Energy Environ Sci, 2011, 4: 2085-2089

18 Heremans JP, Wiendlocha B, Chamoire AM. Resonant levels in bulk thermoelectric semiconductors. Energy Environ Sci, 2012, 5: 5510-5530

19 Heremans JP, Jovovic V, Toberer ES, et al. Enhancement of thermoelectric efficiency in $\mathrm{PbTe}$ by distortion of the electronic density of states. Science, 2008, 321: 554-557

20 Jian Z, Chen Z, Li W, et al. Significant band engineering effect of YbTe for high performance thermoelectric PbTe. J Mater Chem C, 2015, 3: 12410-12417

21 Pei Y, Wang H, Snyder GJ. Band engineering of thermoelectric materials. Adv Mater, 2012, 24: 6125-6135

22 Ginting D, Lin CC, Rathnam L, et al. High thermoelectric performance due to nano-inclusions and randomly distributed interface potentials in N-type $\left(\mathrm{PbTe}_{0.93-x} \mathrm{Se}_{0.07} \mathrm{Cl}_{x}\right)_{0.93}(\mathrm{PbS})_{0.07}$ composites. J Mater Chem A, 2017, 5: 13535-13543

23 Chen Z, Ge B, Li W, et al. Vacancy-induced dislocations within grains for high-performance PbSe thermoelectrics. Nat Commun, 2017, 8: 13828

24 Chen Z, Jian Z, Li W, et al. Lattice dislocations enhancing thermoelectric $\mathrm{PbTe}$ in addition to band convergence. Adv Mater, 2017, 29: 1606768

25 Yang L, Chen ZG, Hong M, et al. n-type Bi-doped PbTe nanocubes with enhanced thermoelectric performance. Nano Energy, 2017, 31: 105-112

$26 \mathrm{Yu}$ Y, Zhang S, Mio AM, et al. Ag-segregation to dislocations in PbTe-based thermoelectric materials. ACS Appl Mater Interfaces, 2018, 10: 3609-3615

27 He J, Zhao LD, Zheng JC, et al. Role of sodium doping in lead chalcogenide thermoelectrics. J Am Chem Soc, 2013, 135: 46244627

28 Yamini SA, Ikeda T, Lalonde A, et al. Rational design of p-type thermoelectric PbTe: temperature dependent sodium solubility. J Mater Chem A, 2013, 1: 8725-8730
29 Cai B, Li J, Sun H, et al. Sodium doped polycrystalline SnSe: High pressure synthesis and thermoelectric properties. J Alloys Compd, 2017, 727: 1014-1019

30 Kang Y, Zhang Q, Fan C, et al. High pressure synthesis and thermoelectric properties of polycrystalline $\mathrm{Bi}_{2} \mathrm{Se}_{3}$. J Alloys Compd, 2017, 700: 223-227

31 Zhu PW, Jia X, Chen HY, et al. Giant improved thermoelectric properties in $\mathrm{PbTe}$ by HPHT at room temperature. Chem Phys Lett, 2002, 359: 89-94

32 Yang M, Zhu H, Li H, et al. Electrical transport and thermoelectric properties of $\mathrm{PbTe}_{1-x} \mathrm{I}_{x}$ synthesized by high pressure and high temperature. J Alloys Compd, 2017, 696: 161-165

33 Zhang J, Xu B, Wang LM, et al. High-pressure synthesis of phonon-glass electron-crystal featured thermoelectric $\mathrm{Li}_{x} \mathrm{Co}_{4} \mathrm{Sb}_{12}$. Acta Mater, 2012, 60: 1246-1251

34 Badding JV. High-pressure synthesis, characterization, and tuning of solid state materials. Annu Rev Mater Sci, 1998, 28: 631-658

35 Brazhkin VV. High-pressure synthesized materials: treasures and hints. High Pressure Res, 2007, 27: 333-351

36 Mii H, Senoo M, Fujishiro I. Solid solubility of Si in Al under high pressure. Jpn J Appl Phys, 1976, 15: 777-783

37 Prinz F, Argon AS. Dislocation cell formation during plastic deformation of copper single crystals. Phys Status Solidi A, 1980, 57: 741-753

38 Wang H, Bahk JH, Kang C, et al. Large enhancement in the thermoelectric properties of $\mathrm{Pb}_{0.98} \mathrm{Na}_{0.02} \mathrm{Te}$ by optimizing the synthesis conditions. J Mater Chem A, 2013, 1: 11269-11278

39 Crocker AJ, Rogers LM. Valence band structure of PbTe. J Phys Col, 1968, 29: C4-129-132

40 Caillat T, Borshchevsky A, Fleurial JP. Properties of single crystalline semiconducting $\mathrm{CoSb}_{3}$. J Appl Phys, 1996, 80: 4442-4449

41 Yamini SA, Mitchell DRG, Gibbs ZM, et al. Heterogeneous distribution of sodium for high thermoelectric performance of p-type multiphase lead-chalcogenides. Adv Energy Mater, 2015, 5: 1501047

42 Ravich IUI, Efimova BA, Smirnov IA. Semiconducting lead chalcogenides. New York: Plenum Press, 1970

43 Kim HS, Gibbs ZM, Tang Y, et al. Characterization of Lorenz number with Seebeck coefficient measurement. APL Mater, 2015, 3: 041506

44 Klemens PG. The Scattering of Low-Frequency Lattice Waves by Static Imperfections. Proc Phys Soc Sec A, 1955, 68: 1113-1128

Acknowledgements This work was supported by the National Natural Science Foundation of China (51525205, 51421091, and 51722209), and the Key Basic Research Project of Hebei (14961013D).

Author contributions $\mathrm{Xu} \mathrm{B}$ and Tian Y conceived the project. Cai B synthesized the samples. Cai B, Li J, Sun H, and Zhang L performed the XRD, SEM, EPMA, and thermoelectric properties measurements. Liu Z and $\mathrm{He} \mathrm{J}$ performed the Hall Measurements. $\mathrm{Hu} \mathrm{W}, \mathrm{Yu} \mathrm{D}$, and Zhao Z performed the TEM measurements. Cai B, Hu W, and Xu B analyzed the data. Cai B, Hu W, Xu B, and Tian Y wrote the paper. All authors contributed to the general discussion.

Conflict of interest The authors declare no conflict of interest. 


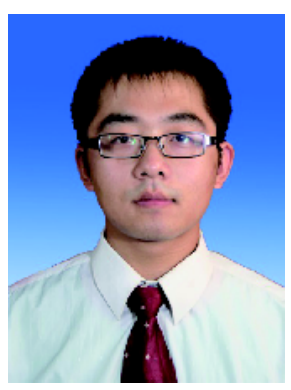

Bowen Cai is a PhD candidate of the College of Materials Science and Engineering, Yanshan University. He joined Prof. Yongjun Tian's group in 2011 and his current research interests include high pressure technology and thermoelectric materials.

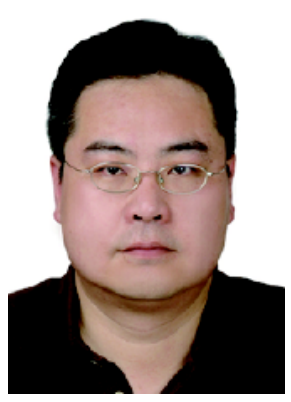

Bo Xu is a professor of the College of Materials Science and Engineering, Yanshan University. He received his PhD from the University of Nebraska-Lincoln (2002). After postdoctoral work at the University of Maryland, College Park, he joined the State Key Laboratory of Metastable Materials Science and Technology, Yanshan University in 2006. His research interests include superhard materials and thermoelectric materials.

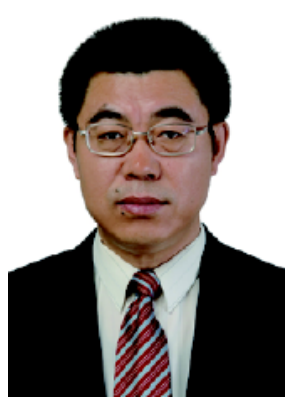

Yongjun Tian is a professor of the College of Materials Science and Engineering, Yanshan University. He received his $\mathrm{PhD}$ from the Institute of Physics, Chinese Academy of Sciences, in 1994, and worked as a postdoctoral fellow in the Universität Jena supported by the Humboldt Research Fellowships from 1996 to 1998. His research interests include design and synthesis of novel metastable materials.

\section{钠掺杂碲化铅热电材料的高压合成及性能研究}

蔡博文, 李江华, 孙浩, 张隆, 徐波 ${ }^{*}$, 胡文涛, 于栋利, 何巨龙, 赵智胜, 柳忠元, 田永君 ${ }^{*}$

摘要 尽管钠可以对碲化铅进行有效的p型掺杂, 但其较低的固溶度限制了对掺杂样品热电性能的全面优化. 本工作采用高压合成方法合 成钠掺杂的碲化铅样品. 结构及成分分析表明样品具有典型的岩盐矿结构, 且钠的含量显著提高. 相应的, $\mathrm{Na}_{0.03} \mathrm{~Pb}_{0.97} \mathrm{Te}_{\mathrm{F}}$ 品的载流子浓度 也提高至 $3.2 \times 10^{20} \mathrm{~cm}^{-3}$. 此外, 显微结构分析确认在高压合成样品的晶粒中形成了高密度的位错. 受益于增强的功率因数和大大抑制晶格 热导率, $\mathrm{Na}_{0.03} \mathrm{~Pb}_{0.97} \mathrm{Te}$ 样品的热电优值达到 1.7. 该工作展示了压力在合成碲化铅基热电材料中的优势. 